\title{
Classification of palm oil fresh fruit bunch using multiband optical sensors
}

\author{
Agung W. Setiawan, Richard Mengko, Ayu P.H. Putri, Donny Danudirdjo, Alfie R. Ananda \\ School of Electrical Engineering and Informatics, Institut Teknologi Bandung, Indonesia
}

\begin{tabular}{l} 
Article Info \\
\hline Article history: \\
Received Jan 5, 2018 \\
Revised Jan 19, 2019 \\
Accepted Mar 19, 2019 \\
\hline
\end{tabular}

\section{Keywords:}

Optical sensing

Palm oil content

Ripeness estimation

Visible-near infrared sensor

\begin{abstract}
This study investigated optical sensor system consist of sixteen light emitting diode (LED) in visible/near infrared region to detect palm oil fresh fruit bunch (FFB) quality. Practically, experience grader assessed FFB quality by its ripeness based on external features such as colour and number of detached fruitlets. However, different seed and plantation management resulting in FFB quality variation. Same external features not linearly correlate with FFB oil content that corresponding with industrial needs. The $660 \mathrm{~nm}$ LED is choosen to be used to estimate the oil content of FFB. Using linear discriminant analysis (LDA) with Mahalanobis distance, the accuracy of the systems is $79.8 \%$ and $88.2 \%$. From 33 FFB oil content measurement, grader misclassified 4 out of 17 FFB as ripe FFB but with low oil content $(<17.5 \%)$ and misclassified 7 out of 16 FFB as unripe but with high oil content $(>=17.5 \%)$. Classifying model build from FFB from main plantation then tested to evaluate FFB from smallholder. Classification model generated from FFB oil content data showed more accurate result compared to model generated from visual inspection $66.7 \%$ compared to $52.1 \%$. Model accuracies attained by Discriminant Analysis (DA) and k-Nearest Neighbors $(\mathrm{k}-\mathrm{NN})$ were $79.8 \%$ and $80.7 \%$, respectively based on grader evaluation. Model accuracies based on FFB oil content was $88.2 \%$ for both classifying algorithms.
\end{abstract}

Copyright (C) 2019 Institute of Advanced Engineering and Science. All rights reserved.

\section{Corresponding Author:}

Agung W. Setiawan,

School of Electrical Engineering and Informatics,

Institut Teknologi Bandung,

St. Ganesa No. 10, Bandung 40132, Indonesia.

Email: awsetiawan@stei.itb.ac.id

\section{INTRODUCTION}

According to The United States Department of Agriculture, in 2016, Indonesia supplied more than half of the global palm oil market [1]. Palm oil Fresh Fruit Bunch (FFB) quality depends on quantity and quality of oil that can be extracted from the bunch. Ripe FFB has more oil than unripe bunch and have less free fatty acid compared to overripe bunch [2]. Oil content in palm oil mesocarp and kernel increases along with palm oil fresh fruit bunches (FFB) ripening process. One of ripeness indication is when fruitlets easy to detached from the bunch be seen in Figure 1. Bunches with 50-200 loose fruits had oil/bunch 1.9\% higher than a bunch with one loose fruit [3].

There are three palm oil varieties, that are nigrescens, virecens, and albenscens. The ripeness of virecens and albenscens varieties can be seen by the color. For virecens, the color of the FFB turn to orange when its ripe. Sabri, et al. has developed camera-based system to detect the FFB ripeness [4]-[12]. In Indonesia, the virecens and albenscens is very rare. The most variety that is grown in Indonesia is nigrescens variety. It is very difficult to assess the FFB ripeness of this variety. There is no color changing when it is under-ripe, ripe, and over-ripe. 


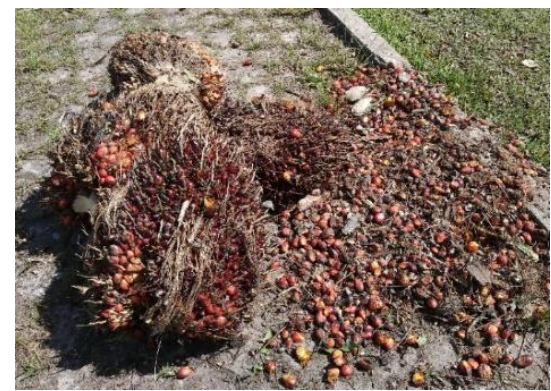

Figure 1. Ripe palm oil fresh fruit bunches with detached fruit

In practical, industry purchased palm oil FFB from smallholder based on FFB ripeness. Conventionally, oil palm FFB ripeness assessed by grider by counting the number of detached fruits per bunch and discoloration. Unripe and overripe FFB return to small holder. Because of grader only look at external feature of FFB, smallholder can detached fruit from FFB so it seen like ripe FFB. This grader approach is so subjective. So, the main problem or research question is how to classified the FFB ripeness of the nigrescens variety objectively.

There are some non-destructive techniques to classified FFB ripeness have been studied by many researchers. Junkwon, et al. introduce hyperspectral-based to grade the FFB ripeness. They found that the classification for four level of FFB ripeness can be done using reflectance value of Near Infrared (NIR) spectrum at $750 \mathrm{~nm}$ and develop the model for oil content prediction [13]. But, hyperspectral imaging tends to have redundant feature and make decreasing in classification accuracy [14]. In 2014, Makky and Soni record diffuse reflectance using fiber reflection probes that provided spectral information between 250 and $1000 \mathrm{~nm}$. They successfully classified seven fraction FFB ripeness using spectral information from 400, 540, 560, 590, 670, 800, 910, 940 and $1000 \mathrm{~nm}$. And also, they develop a model for oil content prediction using spectral data from 440, 470, 480, 510, 610, 690, 720, 750, 760, 880, 900, 910,940, 980, 990 and $1000 \mathrm{~nm}$ [15]. Chemometric analysis using visible and near infrared spectrum were used to obtain internal properties of FFB. It is important to introduce the current technology in palm oil industry. The ultimate goals are to increase the palm oil plantation and factory [8]. In practical application, the rapid and non-destructive NIR technique has potential use for classifying oil palm fresh fruit into ripeness grades. Non-destructive and rapid NIR technique can be used to classify FFB maturity level [16]-[23]. Figure 2 shows the proposed systems that is consists of a silicon based photodetector and 16 LEDs designed in the same plane.

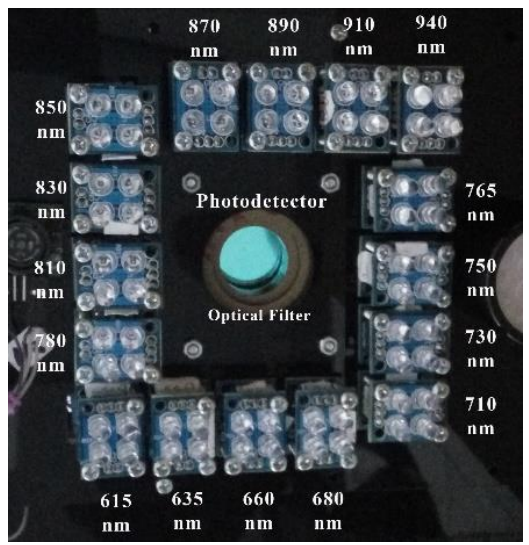

Figure 2. Proposed systems

\section{RESEARCH METHOD}

\subsection{Sample preparation and optical sensor}

This study was carried out on late March to early April 2016 in Riau Province, Indonesia. In this study 191 FFB collected with two ripeness categories, ripe and unripe. One hundred and twenty FFB sample were taken from main plantation and 71 FFB from smallholders. Ripeness class was determined by grader by visual inspection. 
For each FFB, the spectral data are collected from two side of FFB. Output from the systems is voltage value, describe as relative reflectance value of FFB. Sixteen LED (light emitting diode) from $615 \mathrm{~nm}$ to $940 \mathrm{~nm}$ with about $20 \mathrm{~nm}$ interval were utilised. Combination visible and near infrared spectral have better potentiate for FFB ripeness estimation [24]. Chlorophyll, one of FFB pigment that change during maturity has common absorbance within visible spectrum between 600 and $700 \mathrm{~nm}$ [25]. Molecules interaction with electromagnetic radiation within NIR spectrum arise from overtones and combination bands $\mathrm{O}-\mathrm{H}$ and $\mathrm{C}-\mathrm{H}$ existed in moisture and oil [26].

Figure 2 shows the proposed systems that is consists of a silicon based photodetector and 16 LEDs designed in the same plane. A $600 \mathrm{~nm}$ longpass filter placed in front of photodetector to transmit reflected light greater than $600 \mathrm{~nm}$ and reduce effect of ambient light from external source. The system was powered by $5 \mathrm{~V}$ DC and connected to computer for data acquisition and storage. Data collected from two side FFB, average of these two readings from each FFB used for further analysis. Total 262 spectral data were collected and divide into 191 data training and 71 data test. FFB spectral data from main plantation used for training data and tested for classifying FFB ripeness from smallholders. Classification based on visual inspection then will be compared to FFB oil content inspection. Twenty one sample from main plantation used as training data and 12 sample from small holder used as test data. Classification developed using Linear Discriminant Analysis (LDA) with Mahalanobis distance and k-NN algorithm using Euclidean distance with feature selection. Data analysis was done using SPSS Statistics 20.

FFB oil content are determined through laboratory chemical analysis which are time consuming and labor intensive. Thirty three sample data collected for further analysis. Fruitlets were detached from the bunch and then weight. Thirty fruitlets randomly choose, 10 from outer, 10 from middle, and 10 from inner fruitlets as can be seen in Figure 3. Then, these fruitlets are chopped to separate the fruit's mesocarp. Mesocarp then were dried to remove physical water from the mesocarp. The oil in the mesocarp was extracted using Soxhlet extractor with hexane as solvent. The remaining fiber and solvent were dried and cooled in the desiccator. Sample in every step were weighed. Oil in the mesocarp (Oilm) is calculated with (1).

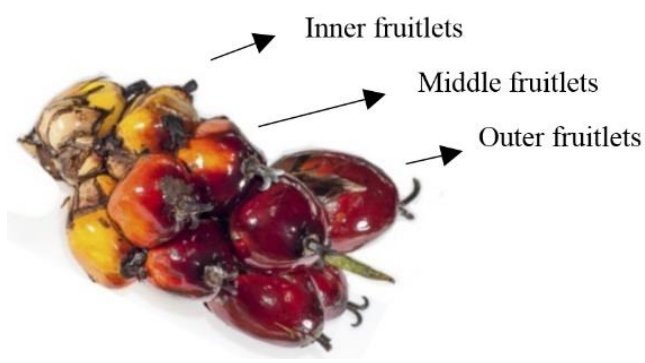

Figure 3. Palm oil spikelet with fruitlets

$$
\% \mathrm{Oil}_{\mathrm{m}}=\frac{\mathrm{W}_{2}-\mathrm{W}_{3}}{\mathrm{~W}_{1}} \times 100 \%
$$

where $\mathrm{W}_{1}$ is mesocarp sample weight $(\mathrm{g}), \mathrm{W}_{2}$ is mesocarp weight after drying $(\mathrm{g})$, and $\mathrm{W}_{3}$ is mesocarp weight after extraction $(\mathrm{g})$. The crude palm oil recovery from the sample FFB is calculated using (2).

$$
\% \text { Oil Content }=\frac{\sum W_{f}}{W_{F F B}} \times \% W_{m} \times \% O i l_{m}
$$

where $\mathrm{W}_{\mathrm{FFB}}$ is $\mathrm{FFB}$ weight $(\mathrm{g}), \mathrm{W}_{\mathrm{f}}$ is fruitlets weight $(\mathrm{g}), \% \mathrm{~W}_{\mathrm{m}}$ is percentage of mesocarp weight from fruitlets $(\%)$, and $\% \mathrm{Oil}_{\mathrm{m}}$ is percentage of mesocarp oil $(\%)$.

\subsection{Classification criteria}

The ripeness estimation basically used to get FFB with high oil content. Misclassification is conducted by the grader could be classifying ripe FFB despite of lower oil yield, vice versa. In this paper, we will investigate classification algorithm robustness based on external feature evaluated by grader and intrinsic criteria based on FFB oil yield. This flowchart of the classification algorithm can be seen in Figure 4. 


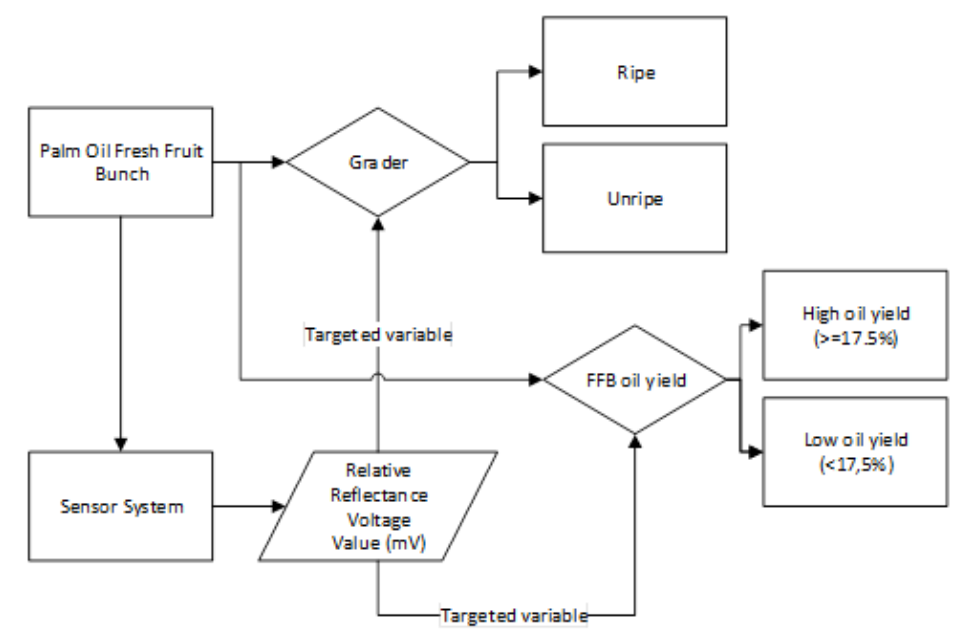

Figure 4. Effects of selecting different switching under dynamic condition

In this study, Euclidean and Mahalanobis distance were used to distinguish between model classes assessed by grader and FFB oil yield. Euclidean distance were used to cluster similar data points into the same clusters, while Mahalanobis measure dissimilar or distant data points are placed into different clusters [27]. Between two data point $\mathrm{x}$ and $\mathrm{y}$, Euclidean distance measured by (3) and Mahalanobis distance measured by (4).

$$
\begin{aligned}
& E D=\sqrt{\sum_{i=1}^{n}\left(x_{i}-y_{i}\right)^{2}} \\
& M D=\sqrt{(x-y) \mathrm{S}^{-1}(x-y)^{T}}
\end{aligned}
$$

where $\mathrm{S}$ is the covariance matrix of the dataset.

\section{RESULTS AND ANALYSIS}

Average relative reflectance voltage value from 16 LEDs is used to differentiate two FFB ripeness categories, ripe and unripe. Using the box-and-whisker plots, outlier samples indicated as dot mark in the box plot were removed from the dataset. Thus total number of samples for ripe and unripe class was 57 and 52 , respectively. Training dataset for FFB oil content were 17 FFB with oil content more than $17.5 \%$ (high oil content) and 4 FFB with oil content less than $17.5 \%$ (low oil content). Four high oil content outlier data removed from dataset. Voltage differentiation between two classes of ripeness almost found in all LED. The box-and-whisker plots of $615 \mathrm{~nm}, 635 \mathrm{~nm}, 660 \mathrm{~nm}$, and $830 \mathrm{~nm}$ are shown in Figure 5.

The differences of voltage value in visible region correlated with change of color due to chloropyll presence that have absorbance in $660 \mathrm{~nm}$ [10]. Palm oil FFB color become more reddish during ripening. According to the Ikemefuna and Adamson, the major pigment changes associated with ripening proses were decreasing the chlorophyll and the massive accumulation of carotenes [28].

Modelling of FFB ripeness uses stepwise approach for variable selection, starts by selecting the most discriminating variable and add new variable in stepwise manner, a combination of forward selection and backward elimination. To found the most discriminative variable, F-test is performed at each step of the process. In this study, for the selection of LED wavelength set at 0.05 for the inclusion variable and 0.1 for removal variable. A summary of the results from stepwise procedure, including the wavelength selection presented in Table 1. This wavelength was selected as the most important wavelength for discriminating between treatment. Different wavelength obtained for classification based on FFB oil content. Only $660 \mathrm{~nm}$ LED include to the model. Using linear discriminant analysis (LDA) with Mahalanobis distance, model accuracy $79.8 \%$ and $88.2 \%$ was obtained for model that generated based on grader evaluation and FFB oil content, respectively. This model was used for evaluating FFB quality from smallholder and accuracy obtained by $52.1 \%$ and $66.7 \%$ for external feature criteria and FFB oil content, respectively. Model that generated based on FFB oil content showed higher rate of accuracy. 

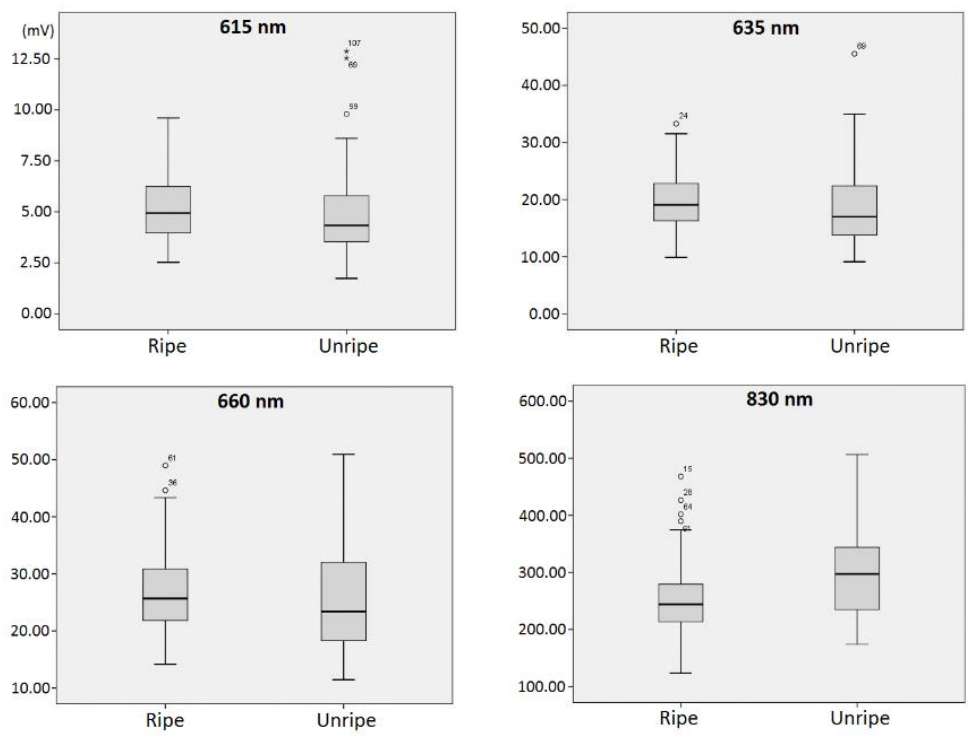

Figure 5. Box-and Whisker plots representing relative reflectance voltage value of ripe and unripe palm oil fresh fruit bunches

Table 1. Variables in the analysis

\begin{tabular}{cccc}
\hline LED Wavelengths $(\mathrm{nm})$ & Tolerance & Sig. of F to Remove & Min. D Squared \\
\hline LED 765 nm & 1.000 & .000 & \\
LED 765 nm & .619 & .000 & .078 \\
LED 680 nm & .619 & .000 & .883 \\
LED 765 nm & .152 & .000 & .954 \\
LED 680 nm & .558 & .000 & .930 \\
LED 890 nm & .201 & .016 & 2.076 \\
LED 765 nm & .150 & .000 & 1.061 \\
LED 680 nm & .036 & .001 & 2.039 \\
LED 890 nm & .201 & .014 & 2.293 \\
LED 660 nm & .040 & .046 & 2.419 \\
\hline
\end{tabular}

Ripe FFB correlated with higher oil yield than unripe FFB, but in the Figure 6 showed that grader tends to underestimate main plantation FFB oil yield and overestimate smallholder FFB oil yield. Grader misclassified 4 out of 17 FFB as ripe FFB but with low oil content and misclassified 7 out of 16 FFB as unripe but with high oil content. Internal quality of FFB hardly determined only from visual inspection.

Different classification algorithm was used to get better accuracy. K-NN is a distance based method in which the training dataset is stored so that a new record may be classified by comparing it with the most similar records in the training set. The number of nearest neighbors tested ranged from 3 to 5 . The $\mathrm{k}$ value used for analysis was set to a maximum 5 which was the number that appeared more frequently in the crossvalidation tests. Euclidean distance used to measure similarity. All predictors are standardized to guarantee measured on the same scale. For k-NN model based on grader evaluation, 3 selected predictors was LED 660,615 , and $830 \mathrm{~nm}$ with $\mathrm{k}=5$. For built model based on FFB oil content criteria, 2 predictors were selected, 635 and $615 \mathrm{~nm}$. The accuracy for both model were $80.7 \%$ and $88.2 \%$, respectively.

Table 2 displays the overall classification accuracies achieved by the two classification methods used in this study. Training dataset was built from FFB from main plantation and tested to FFB sample from smallholders. Classification model generated from FFB oil content data showed more accurate result compared to model generated from visual inspection $66.7 \%$ compared to $52.1 \%$. Thus indicating that FFB oil content was more robust variable for evaluating variant of palm oil FFB than external feature such as colour and number of detach fruit. 


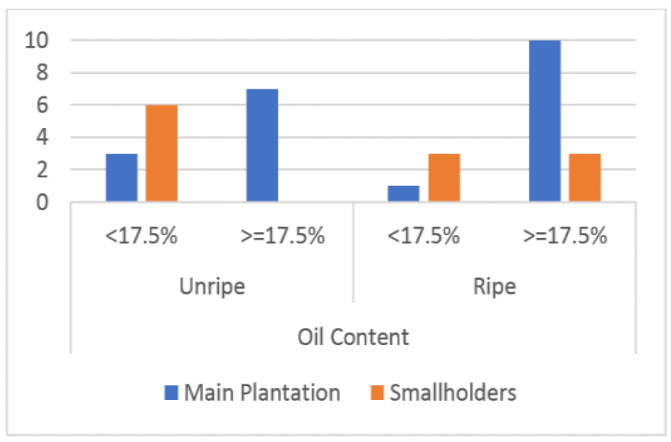

Figure 6. Comparison of ripeness estimation and fresh fruit bunches oil content

Table 2. Average classification accuracies using discriminant and KNN classifier for palm oil fresh fruit bunch quality prediction based on grader evaluation and oil content

\begin{tabular}{ccccc}
\hline \multirow{2}{*}{ Class } & \multicolumn{2}{c}{ Linear Discriminant Analysis } & \multicolumn{2}{c}{ k Nearest Neighbour } \\
& Calibration & Validation & Calibration & Validation \\
\hline Classification based on Grader Evaluation & & & \\
Overall & 79.8 & 52.1 & 80.7 & 62 \\
Unripe & 67.3 & 51 & 69.2 & 68 \\
Ripe & 91.2 & 54 & 91.2 & 50 \\
Classification based on FFB Oil Content & & & \\
Overall & 88.2 & 66.7 & 88.2 & 50 \\
$<17.5 \%$ & 100 & 55.6 & 75 & 33.3 \\
$>=17.5 \%$ & 84.6 & 100 & 92.3 & 100 \\
\hline
\end{tabular}

\section{CONCLUSION}

The combination of visible and near infrared spectrum in this sensor system can potentially use to determining palm oil fresh fruit bunch quality. Learning algorithm can be built based on external feature and internal quality of palm oil FFB. Learning algorithm based on FFB oil content have better performance for classification variety of palm oil FFB and represent better quality as potential oil extraction rate. The $660 \mathrm{~nm}$ LED is choosen to be used to estimate the oil content of FFB. Using linear discriminant analysis (LDA) with Mahalanobis distance, the accuracy of the systems is $79.8 \%$ and $88.2 \%$. From 33 FFB oil content measurement, grader misclassified 4 out of $17 \mathrm{FFB}$ as ripe FFB but with low oil content $(<17.5 \%)$ and misclassified 7 out of 16 FFB as unripe but with high oil content $(>=17.5 \%)$. Classifying model build from FFB from main plantation then tested to evaluate FFB from smallholder. Classification model generated from FFB oil content data showed more accurate result compared to model generated from visual inspection $66.7 \%$ compared to $52.1 \%$. Model accuracies attained by Discriminant Analysis (DA) and k-Nearest Neighbors (k-NN) were $79.8 \%$ and $80.7 \%$, respectively based on grader evaluation. Model accuracies based on FFB oil content was $88.2 \%$ for both classifying algorithms.

\section{REFERENCES}

[1] United States Department of Agriculture. (2016, June 9). Retrieved from http://apps.fas.usda.gov/psdonline/circulars/oilseeds.pdf

[2] M. Makky, et al., "Automatic non-destructive quality inspection system for oil palm fruits," Int. Agrophys vol. 28, pp. 319-329, 2014.

[3] R. Corley and P. Tinker, "The Oil Palm," 4th edition. Berlin: Blackwell Science, 2003.

[4] R. Singh, et al., "The oil palm VIRESCENS gene controls fruit colour and encodes a R2R3-MYB," Nature Communications, vol. 5, pp. 1-8, 2014.

[5] K.K. Loo, et al., "Virescens colour change and oil accumulation in correlation with ripeness in oil palm fruits," 2nd International Conference on Plant Science \& Physiology, 2017.

[6] N. Sabri, et al., "Evaluation of Color Models for Palm Oil Fresh Fruit Bunch Ripeness Classification," Indonesian Journal of Electrical Engineering and Computer Science (IJEECS), vol. 11, no. 2, pp. 549-557, 2018.

[7] M. Makky and P. Soni, "Development of an automatic grading machine for oil palm fresh fruits bunches (FFBs) based on machine vision," Computers and electronics in agriculture, vol. 93, pp. 129-139, 2013.

[8] B. Pamornnak, et al., "An automatic and rapid system for grading palm bunch using a Kinect camera," Computers and Electronics in Agriculture, vol. 143, pp. 227-237, 2017.

[9] A. Jaffar, et al., "Photogrammetric grading of oil palm fresh fruit bunches," Int. J. Mech. Mechatron. Eng, vol. 9, pp. 18-24, 2009. 
[10] J. Roseleena, et al., "Assessment of palm oil fresh fruit bunches using photogrammetric grading system," International Food Research Journal, vol. 18, no. 3, 2011.

[11] N. Sabri, et al., "Palm oil fresh fruit bunch ripeness grading identification using color features," Journal of Fundamental and Applied Sciences, vol. 9, no. 4S, pp. 563-579, 2017.

[12] S. Utom, et al., "Non-Destructive Oil Palm Fresh Fruit Bunch (FFB) Grading Technique Using Optical Sensor," International Journal of Integrated Engineering, vol. 10, no. 1, pp. 35-39, 2018.

[13] P. Junkwon, et al., "Hyperspectral imaging for nondestructive determination of internal qualities for oil palm (Elaeis guineensis Jacq. var. tenera)," Agricultural Information Research, vol. 18, pp. 130-141, 2009.

[14] B. Pamornnak, et al., "Oil content determination scheme of postharvest oil palm for mobile devices," Biosystems Engineering, vol. 134, pp. 8-19, 2015.

[15] A. Taparugssanagorn, et al., "A non-destructive oil palm ripeness recognition system using relative entropy," Computers and Electronics in Agriculture, vol. 118, pp. 340-349, 2015.

[16] N. Fadilah, et al., "Intelligent color vision system for ripeness classification of oil palm fresh fruit bunch," Sensors, vol.12, no. 10, pp. 14179-14195, 2012.

[17] M.R. Puttaswamy and P. Balamurugan, "Neural Network Approach to Identify Hyperspectral Image Content," International Journal of Electrical and Computer Engineering (IJECE), vol. 8, no. 4, pp. 2115-2125, 2018.

[18] M. Makky and P. Soni, "In situ quality assessment of intact oil palm fresh fruit bunches using rapid portable noncontact and non-destructive approach," Journal of Food Engineering, vol. 120, pp. 248-259, 2014.

[19] K.C. Goh, et al., "Evolution of Precision Agriculture Computing towards Sustainable Oil Palm Industry," Indonesian Journal of Electrical Engineering and Computer Science(IJEECS), vol 11, no. 2, pp. 725-732, 2018.

[20] D.D. Silalahi, et al., "Near infrared spectroscopy: a rapid and non-destructive technique to assess the ripeness of oil palm (Elaeis guineensis Jacq.) fresh fruit," Journal of Near Infrared Spectroscopy, vol. 24, no. 2, pp. 179-190, 2016.

[21] S. Kasemsumran, et al., "A feasibility study on non-destructive determination of oil content in palm fruits by visible-near infrared spectroscopy,” Journal of Near Infrared Spectroscopy, vol 20, no. 6, pp. 687-694, 2012.

[22] K.N. Basri, et al., "Classification and quantification of palm oil adulteration via portable NIR spectroscopy," Spectrochimica Acta Part A: Molecular and Biomolecular Spectroscopy, vol. 173, pp. 335-342, 2017.

[23] H.A. Rahim and S.N.N.A. Rani, "Classification of Fatty Fat Acid in Palm Oil Using Near Infrared Spectroscopy," Sensors \& Transducers, vol. 156, no. 9, pp. 247-250, 2013.

[24] O.M.B. Saeed, et al., "Classification of oil palm fresh fruit bunches based on their maturity using portable fourband sensor system," Computers and Electronics in Agriculture, vol. 82, pp. 55-60, 2012.

[25] H.K. Lichtenthaler and C. Buschmann, "Chlorophylls and Carotenoids: Measurement and Characterization by UVVIS Spectroscopy," Current Protocols in Food Analytical Chemistry, pp. F4.3.1-F4.3.8, 2001.

[26] D-W. Sun, "Hyperspectral Imaging for Food Quality Analysis and Control”. San Diego: Academic Press, 2010.

[27] A.S. Shirkhorshidi, et al., "A Comparison Study on Similarity and Dissimilarity Measures in Clustering Continuous Data," PLOS ONE, vol. 10, no. 12, 2015.

[28] J. Ikemefuna and I. Adamson, "Chlorophyll And Carotenoid Changes In Ripening Palm Fruit, Elaeis Guineensis," Phytochemistry, vol. 23, no. 7, pp.1413-1415, 1984.

\section{BIOGRAPHIES OF AUTHORS}

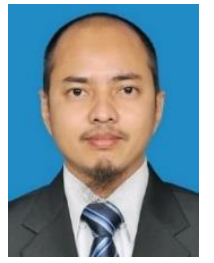

Agung Wahyu Setiawan was born in 1982. He receives the bachelor, master, and doctoral degree in electrical engineering from Institut Teknologi Bandung (ITB), Indonesia, in 2005, 2008, and 2013, respectively. He is currently faculty member of School of Electrical Engineering and Informatics, ITB. His research interests include medical signal \& image processing for e-health application, biomedical spectroscopy. Dr. Setiawan is a member of the IEEE, professional engineer (IPM) and ASEAN Engineer Registered.

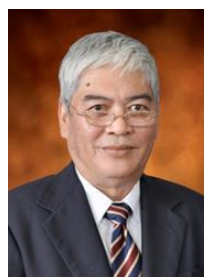

Richard Mengko graduated from Institut Teknologi Bandung (ITB) in 1978 with bachelor of engineering degree. He then advanced and received his doctoral degree from Institut National Polytecnique de Grenoble - France in 1985. He is faculty member of School of Electrical Engineering and Informatics. His research interests include medical image and signal processing. 


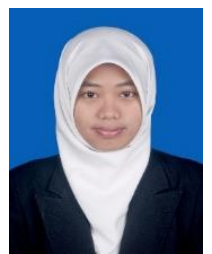

Ayu P.H. Putri receives the bachelor degree in pharmacy and pharmacist from the Institut Teknologi Bandung (ITB), Indonesia, in 2010 and 2012, respectively. She then advanced and received his master of engineering degree (Biomedical Engineering) from Institut Teknologi Bandung in 2017.

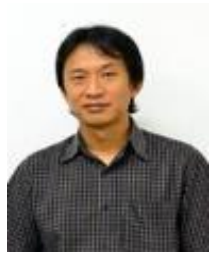

Donny Danudirdjo receives the bachelor and master degree in electrical engineering from Institut Teknologi Bandung (ITB), Indonesia, in 2005 and 2007. He then advanced and received his doctoral degree from The University of Tokyo - Japan in 2013. He is currently faculty member of School of Electrical Engineering and Informatics. His research interests include medical imaging and signal processing.

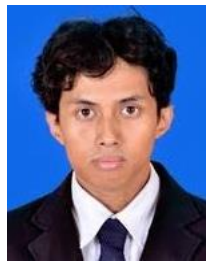

Alfie R. Ananda receives the bachelor degree in electrical engineering from the Institut Teknologi Nasional (ITENAS), Bandung, Indonesia, in 2015, respectively. 